\title{
A novel non-enzyme sensor based on a PDDA-RGO/Pt NPs nanocomposite for electrochemical detection of ascorbic acid
}

\author{
Guanglei Chu ${ }^{1,2,3}$ Guangxian Wang ${ }^{1,2,3}$, Yao Yao ${ }^{1,2,3}$, Xingshuang An ${ }^{1,2,3}$, Yanyan Zhang ${ }^{* 1,2,3}$ \\ ${ }^{1}$ School of Agriculture Engineering and Food Science, Shandong University of Technology, No.12 \\ Zhangzhou Road, Zibo 255049, Shandong Province, P.R. China. \\ ${ }^{2}$ Shandong Provincial Engineering Research Center of Vegetable Safety and Quality Traceability, \\ No.12 Zhangzhou Road, Zibo 255049, Shandong Province, PR China. \\ ${ }^{3}$ Zibo City Key Laboratory of Agricultural Product Safety Traceability \\ *E-mail: zyyan1104@163.com
}

doi: $10.20964 / 2019.12 .47$

Received: 26 July 2019 / Accepted: 24 September 2019 / Published: 29 October 2019

\begin{abstract}
Enzyme-based sensors exhibit some inevitable shortcomings based on short storage times, poor stability and high cost. In this paper, we used platinum nanoparticles (Pt NPs) instead of enzymes to catalyze the detection of ascorbic acid; thus, we developed a new non-enzymatic sensor electrocatalyst for ascorbic acid detection. Poly dimethyl diallyl ammonium chloride (PDDA)-modified graphene not only showed excellent conductivity and solubility but also increased the modification ability of the nanomaterials. Platinum nanoparticles show a strong catalytic effect on ascorbic acid. By binding both these materials together and modifying them on glassy carbon electrodes, a non-enzymatic sensor based on a PDDA-functionalized reduced graphene oxide-platinum nanoparticles nanocomposite was built. TEM, EDS and FT-IR were used for characterizing the morphology of the samples. The electrochemical properties of the PDDA-reduced graphene oxide-platinum nanoparticles (PDDARGO/Pt NPs) electrodes were studied by cyclic voltammetry. The results showed that the sensor could be used to detect AA with excellent electrocatalytic activity, a wide linear range of $0.001 \mathrm{mM}-10 \mathrm{mM}$ at $0 \mathrm{~V}$, and a low detection limit of $0.0005 \mu \mathrm{M}(\mathrm{S} / \mathrm{N}=3)$. The repeatability and stability of the sensor was also studied, and the sensor was found to exhibit excellent performance. From an interference study, it was found that interfering substances had little effect on the sensor, with a recovery rate between $96 \%$ and $104 \%$ found in actual sample detection. This method of sensor fabrication provided a potential platform for the detection of other biological substances.
\end{abstract}

Keywords: Non-enzymic sensor; Platinum nanoparticles; Ascorbic acid detection; Reduced graphene oxide; Poly dimethyl diallyl ammonium chloride

\section{$\underline{\text { FULL TEXT }}$}


(C) 2019 The Authors. Published by ESG (www.electrochemsci.org). This article is an open access article distributed under the terms and conditions of the Creative Commons Attribution license (http://creativecommons.org/licenses/by/4.0/). 